\title{
Could Non-elasticity Demand be Blamed for the Raising of House Price in China?
}

\author{
—-Dynamics of a Cournot Game with Inelasticity Demand
}

\author{
Tongxin \\ Economics \&Management Department \\ Shenzhen Graduate school of Harbin University of \\ Technology \\ Shenzhen, China \\ e-mail: sasasam@163.com
}

\author{
Wang Susheng \\ Economics \&Management Department \\ Shenzhen Graduate school of Harbin University of \\ Technology \\ Shenzhen, China \\ e-mail: 110928125@qq.co
}

\begin{abstract}
The Chinese house price was raised rapid and sustain, some scholars thought that the reason is the nonelasticity demand, it is said that the action of collusion of the firms is the maximum of profit. To test if the reason of collusion of housing firms in China was they faced to a nonelasticity demand, so the continuous dynamical system of duopoly Cournot game with constant elasticity demand is derived in our paper, and the stability of this system is studied, finnally the Cournot game with n-competitors is discussed. A general conclusion of existence of Nash-Cournot equilibrium was drew. The collusion of housing firms no came from the profits maximization with non-elasticity demand. The way of land supply which makes increasing marginal cost of house maybe the reason of collusion of housing supply. The conclusion of there are no solution to deal with the rapid and sustain raising of Chinese house price is wrong and Puu and Zhang made mistakes in their papers.
\end{abstract}

Keywords-House price; Collusion; Cournot model; Inelasticity demand; Stability;

\section{INTRODUCTION}

Cournot model descript an industry for oligopoly with linear demand, the elasticity with respect to price for linear demand is from $-\infty$ to 0 . A special case is the housing market in China. On the supply hand, the land on which the house will be built belongs to the government, and the government sell the land to developer to develop, it ensure that have a few supplier in the housing market; on the demand hand, the resident must to buy a house themselves to get a "Household Registered" become a registered permanent residence, and the registered permanent residence will get some benefits such as education of children, unemployment insurance, etc.. It ensures the nonelasticity demand with respect to price.

There was a view in Chinese housing industry that the reason of the continued raising of housing price was they faced to a non-elasticity demand. To test this view, we consider a special situation of a duopoly game, don't like the paper of Cournot (1883), neither like the paper of Puu (1991), Kopel (1996), nor Agiza (1998). We discuss an oligopoly structure with a constant elasticity demand with respect to price but not restrict to 1 , construct a dynamic
Cournot model like Varian (1997), study the time path of supply under the assumption of profit maximization.

Cournot (1883) gave a demand function $p=a-b q$, where $q$ is demand quantity, $p$ is the price that formed by market, the characteristics of linear demand is the constant slope and a variable elasticity. When $p=\frac{a}{2 b}$, the elasticity is 1 , and the elasticity is higher when the price is higher. When the price goes from 0 to $\frac{a}{b}$, the elasticity of demand goes from zero to infinity. Puu, Kopel, and Agiza used a demand function $q=\frac{1}{p}$, the characteristics of this demand is the variable slope and a constant elasticity, $\varepsilon=\frac{d q}{d p} \cdot \frac{p}{q}=1$

respect to price, $\frac{d q}{d p}$ is the derivative of $q$ with respect to $p$, this demand has unitary elasticity at every point.

The special case is the estate market in China. On the supply hand, the land on which the house will be built belongs to the government, and the government sell the land to developer to develop, it ensure that have a few supplier in the estate market; on the demand hand, the resident must to buy a house themselves to get a "Household Registered" become a registered permanent residence, and the registered permanent residence will get some benefits such as education of children, unemployment insurance, etc.. It ensures the inelasticity demand with respect to price.

The paper organized as follows. In section 2, we derive the dynamical system of duopoly Cournot supply faces an inelasticity demand. Section 3, we describe the trace of this dynamical system intuitively. Section 4, a discussion of the general case with n-competitors. The last section is conclusion. 


\section{CONTINOUS DYNAMIC DOUPOLY SUPPLY FACES INELASTICITY DEMAND}

\section{A. An inelasticity demand}

For the reason of convenient, we used an inverse demand function but a demand function of constant elasticity with respect to price:

$$
p=A q^{-\alpha}
$$

Where

$A>0$ is constant;

$\alpha>1$ is constant too;

$p>0$ is price;

$q \geq 0$ is demand.

That means:

$\lg p=\lg A-\alpha \lg q$

So the elasticity of demand respect with price is:

$$
\varepsilon=\frac{d q}{d p} \cdot \frac{p}{q}=-\frac{1}{\alpha}
$$

The absolute value of elasticity, $|\varepsilon|<1$, so it must be an inelasticity demand.

And because of the constant of $\alpha$, so the elasticity is constant, and the inverse demand function $p=A q^{-\alpha}$ is an inelasticity demand function.

\section{B. The continuous Cournot duopoly game}

For reason to the intuitive of description, we choose duopoly game in a two dimensions space. The firm in the duopoly game mediates supply of itself to affect the price and determine the cost; it will affect its revenues and maximize the profit.

At a state of continuous time, we get the dynamical system as follow:

$$
\begin{gathered}
\dot{q}_{1}=\beta_{1} \cdot \frac{\partial \pi_{1}\left(q_{1}, q_{2}\right)}{\partial q_{1}} \\
\dot{q}_{2}=\beta_{2} \cdot \frac{\partial \pi_{2}\left(q_{1}, q_{2}\right)}{\partial q_{2}} \\
\dot{q}=\frac{d q}{d t}, \text { is there }
\end{gathered}
$$

respect to time; $\beta>0$ is the speed of mediate of supply; $\pi$ is the profit, is the function of the supply of two firms; subscripts represent of two firms respectively.

This dynamical system means the firm mediates the supply of itself ( $\frac{d q_{1}}{d t}$ and $\frac{d q_{2}}{d t}$ ) to enlarge the profit $\frac{\partial \pi_{1}\left(q_{1}, q_{2}\right)}{\partial q_{1}}$ and $\quad \frac{\partial \pi_{2}\left(q_{1}, q_{2}\right)}{\partial q_{2}}$ , and the fixed point is the maximum point. If the dynamical system has fixed point ( $\frac{d q_{1}}{d t}=\frac{d q_{2}}{d t}=0$ ), it means has a point $\left(q_{1}^{*}, q_{2}^{*}\right)$ that makes firm 1 chooses $q_{1}^{*}$ when firm 2 chose $q_{2}^{*}$ to maximize the profit of firm $1, \pi_{1}$, and firm 2 chooses $q_{2}^{*}$ when firm 1 chose $q_{1}^{*}$ to maximize the profit of firm $2, \pi_{2}$. The point $\left(q_{1}^{*}, q_{2}^{*}\right)$ makes $\pi_{1}\left(q_{1}^{*}, q_{2}^{*}\right)>\pi_{1}\left(\bar{q}_{1}^{*}, q_{2}^{*}\right)$ (where $\bar{q}_{1}^{*}$ is the supply of firm 1 except $q_{1}^{*}$ ), and $\left(q_{1}^{*}, q_{2}^{*}\right)$ makes $\pi_{2}\left(q_{1}^{*}, q_{2}^{*}\right)>\pi_{2}\left(q_{1}^{*}, \bar{q}_{2}^{*}\right)$ at the same time (where $\bar{q}_{2}^{*}$ is the supply of firm 2 except $q_{2}^{*}$ ).

\section{The dynamics of Cournot duopoly game}

We introduce the demand function into the dynamical system, and analysis the stability of this system.

Firm 1 choose the supply of itself in account of the supply of firm 2 and the total cost of itself to maximize the profit of firm 1, we have:

$$
\pi_{1}\left(q_{1}, q_{2}\right)=p\left(q_{1}, q_{2}\right) \cdot q_{1}-C_{1}\left(q_{1}\right)
$$

As the same, the profit of firm 2 :

$$
\pi_{2}\left(q_{1}, q_{2}\right)=p\left(q_{1}, q_{2}\right) \cdot q_{2}-C_{2}\left(q_{2}\right)
$$

Input the inverse demand function (1) to (6) and (7), the profit functions:

$$
\begin{aligned}
& \pi_{1}=A\left(q_{1}+q_{2}\right)^{-\alpha} \cdot q_{1}-C_{1}\left(q_{1}\right) \\
& \pi_{2}=A\left(q_{1}+q_{2}\right)^{-\alpha} \cdot q_{2}-C_{2}\left(q_{2}\right)
\end{aligned}
$$

We assume that the marginal cost is constant. Input (8) and (9) to (4) and (5), we have:

$$
\left\{\begin{array}{l}
\dot{q}_{1}=\frac{\beta_{1} \cdot\left((1-\alpha) \cdot A \cdot q_{1}+A \cdot q_{2}\right)}{\left(q_{1}+q_{2}\right)^{\alpha+1}} \\
\dot{q}_{2}=\frac{\beta_{2} \cdot\left(A \cdot q_{1}+(1-\alpha) \cdot A \cdot q_{2}\right)}{\left(q_{1}+q_{2}\right)^{\alpha+1}}
\end{array}\right.
$$

$\lim _{\substack{Q_{1} \rightarrow 0 \\ Q_{2} \rightarrow 0}} \dot{q}_{1}=\lim _{\substack{Q_{1} \rightarrow 0 \\ Q_{2} \rightarrow 0}} \dot{q}_{2}=\infty$ , so the only condition for this dynamical system have fixed point is $\alpha=2$, and the fixed point is $q_{1}=q_{2}$

\section{AN INTUITIVE DESCRIPTION BY PHASE DIAGRAM}

To describe the trace of this dynamical system intuitively, we use the phase diagram.

When $q_{1} \neq 0$ and $q_{2} \neq 0$ we have the characteristics line (It is called response line in economics):

$$
\begin{aligned}
& \dot{q}_{1}=\beta_{1} \cdot\left((1-\alpha) \cdot A \cdot q_{1}+A \cdot q_{2}\right)=0 \\
& \dot{q}_{2}=\beta_{2} \cdot\left(A \cdot q_{1}+(1-\alpha) \cdot A \cdot q_{2}\right)=0
\end{aligned}
$$

The curve, $\dot{q}_{1}=0$, divided the space into two spaces, left and right; the curve, $\dot{q}_{2}=0$, divided the space into two spaces, up and down.

A. Case $1, \alpha>2$

When $\alpha>2$, the curve $\dot{q}_{1}=0$ is steeper than $\dot{q}_{2}=0$. The point at left of $\dot{q}_{1}=0$ goes right and at right of 
$\dot{q}_{1}=0$ goes left; the point at up of $\dot{q}_{2}=0$ goes down and at down of $\dot{q}_{2}=0$ goes up. So we get the trace like Figure 1 .

When $\alpha>2$, it means the absolute value of demand elasticity respect with price is less 0.5 , the trace goes to point $(0,0)$ infinitely, but can get the point $(0,0)$.

B. Case 2, $2>\alpha>1$

When $2>\alpha>1$, the curve $\dot{q}_{1}=0$ is flatter than $\dot{q}_{2}=0$. The point at left of $\dot{q}_{1}=0$ goes right and at right of $\dot{q}_{1}=0_{\text {goes left; the point at up of }} \dot{q}_{2}=0_{\text {goes down }}$ and at down of $\dot{q}_{2}=0$ goes up. So we get the trace like Figure 2.

\section{Case 3, $\alpha=2$}

When $\alpha=2$, the curve $\dot{q}_{1}=0$ coincides with $\dot{q}_{2}=0$. So we get the trace like Figure 3.

\section{DISCUSSION}

To discuss the general case of $n_{\text {-competitors, we use a }}$ characteristic determinant. When $q_{1} \neq 0$ and $q_{2} \neq 0$, because the stability of the dynamical system is determined by the signal of characteristic root, the characteristic determinant of dynamical system (10) can be represented by (11)

$$
\left|\begin{array}{cc}
(1-\alpha) \cdot-\lambda & 1 \\
1 & (1-\alpha)-\lambda
\end{array}\right|=0
$$

So the characteristic root is:

$$
\lambda_{1}=2-\alpha, \lambda_{2}=-\alpha
$$

When $\alpha>2$, it means $\lambda_{1}<0$ and $\lambda_{2}<0$, so, $(0,0)$ is a sink.

When $1<\alpha<2$, it means $\lambda_{1}>0$ and $\lambda_{2}<0$, so, $(0,0)$ is a source.

When the numbers of firm increase to 3 , we have:

$$
\left|\begin{array}{ccc}
(1-\alpha)-\lambda & 1 & 1 \\
1 & (1-\alpha)-\lambda & 1 \\
1 & 1 & (1-\alpha)-\lambda
\end{array}\right|=0
$$

So the characteristic root is:

$$
\lambda_{1}=3-\alpha, \lambda_{2}=-\alpha, \lambda_{3}=-\alpha
$$

When $\alpha>3$, it means $\lambda_{1}<0, \lambda_{2}<0$ and $\lambda_{3}<0$, so, $(0,0)$ is a sink.

When $1<\alpha<3$, it means $\lambda_{1}>0, \lambda_{2}>0$ and $\lambda_{3}<0$,so, $(0,0)$ is a source.
When the numbers of firm increase to $n$, and $n>3$, we have:

$$
\left|\begin{array}{cccc}
(1-\alpha)-\lambda & 1 & \cdots & 1 \\
1 & (1-\alpha)-\lambda & \cdots & 1 \\
\vdots & \vdots & \vdots & \vdots \\
1 & 1 & \cdots & (1-\alpha)-\lambda
\end{array}\right|=0
$$

The characteristics function is

$$
((1-\alpha)-\lambda)^{n}-n((1-\alpha)-\lambda)+(n-1)=0
$$

so the characteristic root is:

$$
\lambda_{1}=n-\alpha, \lambda_{2}=-\alpha, \ldots, \lambda_{n}=-\alpha
$$

When $\alpha>n$, it means $\lambda_{1}<0, \lambda_{2}<0$ and $\lambda_{3}<0$, so, $(0,0)$ is a sink.

When $1<\alpha<n$, it means $\lambda_{1}>0, \lambda_{2}>0, \ldots, \lambda_{n}<0$ so, $(0,0)$ is a source.

We get the general conclusion, with $n$-competitors, the bifurcation point is $n$, when $\alpha>n,(0,0)$ is a sink; when $1<\alpha<n,(0,0)$ is a source.

\section{CONCLUSION}

The conclusions of this paper were drawn:

Under the assumption of 0 marginal cost, the stability of a Cournot game was decided by the number of firms, $n$, and the elasticity of demand, $\varepsilon$, when the demand was constant elasticity; when $n \cdot \varepsilon>1$ the time path of supply is diverge, when $n \cdot \varepsilon<1$ the time path of supply is converge to $0, n \cdot \varepsilon=1$ the time path of supply is converge to anywhere that $q_{1}=q_{2}=\cdots q_{n}$.

Non-elasticity demand cannot be blamed for the sustained raising of housing price of China, as the estimate of Chow(Chow, 2010), the elasticity of demand with respect to price is between 0.5 to 0.6 , with such a demand elasticity, the situation of supply converge to 0 is the number of firms less than 2 .

The way of land supply which makes increasing marginal cost of house maybe the reason of collusion of housing supply.

Some industries in China, for example petroleum, have 3 -firms, maybe have incentive to decrease supply because of the non-elasticity demand.

Face to a demand with elasticity from $-\infty$ to 0 , the Cournot game with any competitors will have NashCournot equilibrium. For example, the demand function is $p=a-b q$, when $n=1$ the equilibrium is $q=\frac{a}{2 b}$ and where $|\mathcal{E}|=1$; when $n=2$ the equilibrium is $q_{1}=q_{2}=\frac{a}{3 b}$ and where $|\varepsilon|=\frac{1}{2}$; for all $n$, the 
\[ q_{1}=q_{2}=\cdots=q_{n}=\frac{a}{(n+1) b} \text { and where } \]
equilibrium is $|\varepsilon|=\frac{1}{n}$

T. Puu (1991) made a mistake, the conclusion of chaos for Cournot game came from the arbitrary assumption that the firms knew about the demand and the supply of all players but they mediate the supply of themselves under a naïve assumption that the supply of the others will never be mediated.

$$
\text { Zhang yu-bo (2003) used } p=p_{0}-w q^{2} \text {, }
$$
$\left(0 \leq q \leq \sqrt{p_{0} / w}\right)$ as the inverse demand function, the

elasticity of this demand function is

$$
\varepsilon=-\frac{p w}{2\left(p_{0}-p\right)}
$$
characteristics of this elasticity is monotone increase from $-\infty$ to 0 when the price, $p$, decrease from $p_{0}$ to 0 . It must have a steady state for any number of players in this Cournot game.

\section{REFERENCES}

[1] Cournot A. Recherches sur les Principes Mathematiques de la Theorie des Richesses. Paris: Hachette; 1883

[2] Puu T. Chaos in duopoly pricing. Chaos, Solitons \& Fractals 1991; 1:pp.573-81.

[3] Kopel M. Simple and Complex Adjustment Dynamics in Cournot Duopoly Models. Chaos, Solitons \& Fractals 1996; 7:pp.2031-48.

[4] Agiza HN. Explicit stability zones for Cournot games with 3 and 4 competitors. Chaos, Solitons \& Fractals 1998; 9:pp:1513-7.

[5] [5] Zhang Yu-bo, Dynamic model and stability analysis in oligopoly market, System engineering - theory\&practice 2003(11) 54-59

[6] [6] Zhang Y B,Adaptive dynamic Cournot model of optimizing generating untis' power output under nonlinear market demand[C]//Proccedings of the 16th conference on software Engineering Education and Training.2003,23:80-84

[7] [7] Arvan L. Some examples of dynamic Cournot duopoly with inventory[J].Rand Journal of Economics, 1985,16(4):569-578

[8] [8] Sandal L.K., Dynamic Cournot-competitive harvesting of a common pool resource[J]. Journal of Economic Dynamics and Control,2004,28(9):1781-1799.

[9] [9] Szidarovszky F. Dynamic Cournot oligopoliies with production adjustment cost $[\mathrm{J}]$. Journal of Mathematical Economics,1995,24(1):95-101

[10] [10] Qiu L.D.,On the dynamic efficiency of Bertrand and Cournot equilibria[J]. Journal of Economic Theory, 1997,75(1):213-229

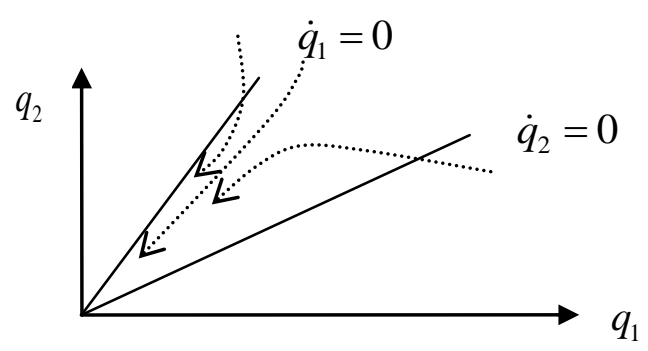

Figure 1. The dynamics of duopoly when $\alpha>2$

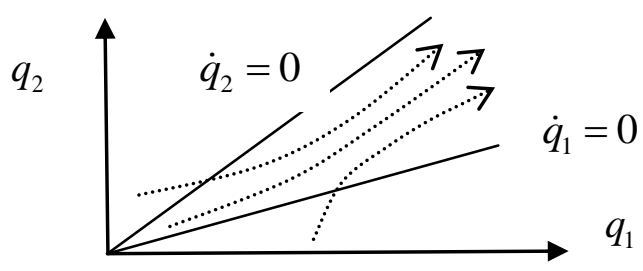

Figure 2. The dynamics of duopoly when $\alpha<2$

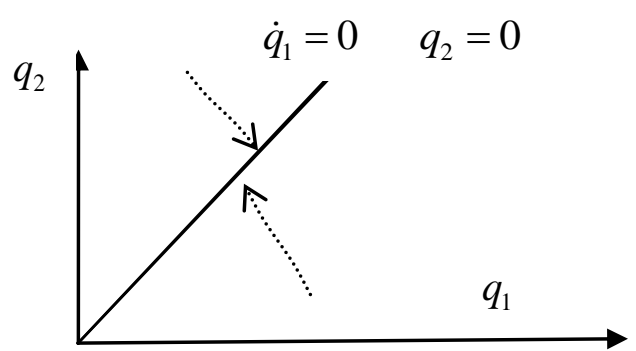


Figure 3. The dynamics of duopoly when $\alpha=2$ 